\title{
Cross-Jurisdictional Analysis
}

\begin{abstract}
This chapter explores the key components and characteristics of the wellbeing approaches taken by Scotland, Wales and Northern Ireland. Despite different origins, there are remarkable similarities between the approaches taken by the devolved legislatures. Each framework blends objective and subjective data and all three prioritise quality of life indicators over environmental and economic indicators. Wallace goes on to argue that the impact of wellbeing frameworks on approaches to government can be seen as setting wellbeing as an overarching goal for government, wellbeing as a conversation to discuss social progress, wellbeing as a framework for public services and wellbeing as an approach to delivering public services.
\end{abstract}

Keywords Indicators - Performance management - Social progress • Public sector reform · Leadership

\section{Towards a Shared Understanding of Wellbeing}

As described in the preceding chapters, each of the devolved governments developed their wellbeing framework to address specific needs. It is interesting therefore to note the extent to which the wellbeing frameworks and approaches have converged (see Table 6.1).

The component parts of the wellbeing framework have coalesced almost completely, consisting of a vision statement, a set of outcomes

J. Wallace, Wellbeing and Devolution, Wellbeing in Politics and Policy, https://doi.org/10.1007/978-3-030-02230-3_6 
Table 6.1 Key components and characteristics of a wellbeing approach to governance

\begin{tabular}{llll}
\hline & Scotland & Wales & Northern Ireland \\
\hline Catalyst & $\begin{array}{l}\text { Performance } \\
\text { management }\end{array}$ & $\begin{array}{l}\text { Sustainable } \\
\text { development }\end{array}$ & Political visioning \\
\hline $\begin{array}{l}\text { Components } \\
\text { Vision statement }\end{array}$ & Yes & Yes & Yes \\
$\begin{array}{l}\text { Outcomes } \\
\text { Indicators }\end{array}$ & 11 & 7 & 16 \\
$\begin{array}{l}\text { Characteristics } \\
\text { Statutory duties }\end{array}$ & 81 & 46 & 49 \\
$\begin{array}{l}\text { Participatory methods } \\
\begin{array}{l}\text { Aligned to sustainable } \\
\text { development goals }\end{array}\end{array}$ & Yes & Yes & No \\
\hline
\end{tabular}

Source Original

and a dashboard of indicators. The dashboard approach is also shared by the UK Office of National Statistics, which measures wellbeing through 42 indicators grouped into ten domains. The difference in the devolved legislatures is the innovation of shifting the measurement dashboard into a broader framework around the purpose of government, and within an outcomes approach.

Scotland, Wales and Northern Ireland have all taken the approach of a dashboard of indicators, rather than an index or use of subjective wellbeing as a headline indicator. And they have done so for the same reasons, they believe that this is the best way to enable the use of wellbeing data in policy development. The indicators share certain characteristics:

- Quantitative: Even those that come from qualitative sources (such as quality of early years education provided) are given numeric values when measured (the number of schools with positive reports).

- Source: They derive from official sources, such as the household surveys, labour force surveys and information from scrutiny bodies (auditors and regulators).

- Mixed: They provide a mix of objective indicators (e.g. crime levels) and subjective indicators (e.g. perceptions of crime). They all include a measure of personal wellbeing, but not the same one. 
- Non-hierarchical: All indicators are given equal weight in the frameworks.

- Cross-cutting: Many indicators cut across more than one domain of wellbeing.

- Comprehensive: Include the key domains of wellbeing that governments are seen as having a legitimate role in influencing.

There are also shared conventions in reporting the indicators. They each report the direction of travel (improving, maintaining or worsening) based on statistically robust changes. The exact calculations differ depending on the type of indicator. They each report with a narrative attached, a description of the change over time and the policy context within which this change occurs. And they all provide further analysis based on socio-demographic groups, to allow for comparison between different sections of society. Scotland updates its websites in 'real time' as soon as new indicators become available, which will be the approach in Wales once established. Northern Ireland does not.

\section{Types of Data}

The similarities and differences in indicators are worth explorations (see Fig. 6.1). To recap from the introduction:

- Objective data may be about people and supplied by people but it is factual data. It can be further subdivided into those that are collected for the jurisdiction as a whole, for example greenhouse gas emissions or productivity, and those that are aggregated from individual level, for example education attainment rates.

- Subjective data is collected from individuals about their own experiences. For example, perceptions of crime. It can be information about individuals (their feelings of confidence, self-esteem or mental health) or their perceptions of places or services (e.g. whether they feel that public services are delivered well in their area).

The number of exact matches between each indicator set is low. In some cases, the differences are due to priorities given to different issues. In Northern Ireland, a number of indicators relate to the post-conflict environment-for example, they measure the proportion who believe their cultural identity is respected by society and the proportion who believe 
- Objective (76\%)

- Subjective (18\%)

- In development (6\%)

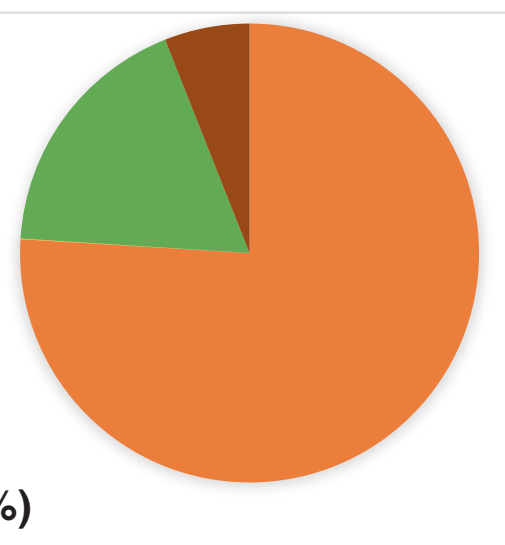

\section{$30 \%$}

Quality of life $40 \%$

Environmental 20\%

Fig. 6.1 Analysis of indicators (Scotland, Wales, Northern Ireland combined) (Source Original)

that all leisure centres, parks, libraries and shopping centres in their area are 'shared and open' to both Protestants and Catholics. Wales continues its interest in cultural identity by measuring the number of Welsh speakers and makes a significant effort to measure future stocks (including historical archives) as well as current conditions. Scotland, with the 
most indicators, includes a large number of measurements that indicate a range of inequalities, and is the only framework to include measures of the subjective views of children and young people.

Other differences are less clearly identified to cultural and political priorities. Some appear to be clear omissions such as the lack of a measure of water quality in Scotland. Others relate to expert disagreements or lack of maturity of the social indicators themselves. Each jurisdiction prefers a different measure of income inequality, for example, which appears to depend on the advice from government statisticians. All clearly aim to measure the quality of jobs, but this is emerging in the social indicator movement and there is no clarity yet on what should be included (White 2018).

These differences show that the development of the frameworks is an art, not a science, those involved are seeking to balance political priorities, available data and stakeholder views. In no case did the civil servants involved run statistical regressions or modelling to identify the 'best fit' indicators either to a dominant indicator within the domain, or to personal wellbeing.

Each of the wellbeing frameworks blends objective and subjective data. The vast majority of the indicators (an average of three-quarters across the three frameworks) are objective indicators. Scotland has a slightly higher proportion of subjective indicators (24\% compared to $17 \%$ and $13 \%$ in Wales and Northern Ireland, respectively).

Objective and subjective data are therefore present in the three wellbeing frameworks, but the priority is to report on objective indicators. The wellbeing frameworks of the devolved governments are more focused on objective fact (education, housing, health, income), rather than citizens' satisfaction with their lives, or measurements of wellbeing that prioritise citizens' ability to exercise control over their own lives. Relating this to the philosophical underpinnings of wellbeing in Chapter 1 , it appears that each government is prioritising a basic needs approach to wellbeing. The measurements of material conditions are almost all objective and the measurements of quality of life are similarly weighted towards the objective.

There are elements of the frameworks that push towards a Capabilities Approach and in particular towards a number of items on the list of capabilities developed by Martha Nussbaum (2006). There are measures of life, bodily health and affiliation in all three frameworks. Northern Ireland measures self-efficacy and locus of control. Wales and Scotland 
measure the capability of 'control' through engagement with decision-making processes. In all jurisdictions, citizens' physical activity is measured, and their cultural participation-but none come close to the concept that Nussbaum thought essential-that of play. There is no measurement of satisfaction with work-life balance in any of the frameworks. The capabilities of senses, imagination and thought are not measured, nor is the practical reason. In excluding these capabilities, each government is inadvertently drawing a line between the business of government and the known contributors to wellbeing. The Northern Ireland framework has never purported to be anything but a framework for the government. Scotland has recently moved closer to the Wales approach of the framework being for the people. Even so, both Scotland and Wales limit inclusion to those areas that the government has a clear and legitimate role.

\section{Domains of Wellbeing}

In terms of the broad categories of wellbeing (quality of life, material conditions and environment), almost half relate to quality of life (49\% across the three frameworks). Wales has the greatest proportion of indicators on environmental issues with 14 out of $46(30 \%)$. Scotland has only 13 out of 81 indicators relating to environmental issues $(16 \%)$, while it has 30 material conditions indicators $(37 \%)$ and 38 quality of life indicators $(47 \%)$. Northern Ireland has the highest proportion of quality of life indicators (55\%), 29\% cover material conditions and environmental indicators account for $16 \%$. The preponderance of quality of life indicators relates not to the science of wellbeing (all were developed through consultation, not statistical methods) but to their relevance to the devolved legislatures core competencies on social policy. All prioritise the quality of life issues that they can have the most direct impact on.

The largest difference is in the extent to which the material conditions indicators are balanced by environmental indicators. In Wales, there are more environmental indicators than material ones $(30 \%$ compared to 24\%). In Scotland and Northern Ireland, the material conditions indicators are given substantially more 'space' in the framework (to reiterate, in Scotland and Northern Ireland 37\% and 29\% of indicators relate to material conditions respectively, but environmental indicators account for only 16\%). Here very starkly we can see the real-world impact of the 
different origins: Scotland and Northern Ireland prioritise quality of life than the economy, Wales prioritises quality of life and then the environment. Matching the beyond GDP origins of the Welsh framework, the power of the economy is far reduced in this framework and subservient to quality of life and the environment-not the dominant force.

\section{Structure of the Frameworks}

There are other similarities in the development of the structure of the wellbeing frameworks. In Scotland and Wales, early versions had two levels. In Scotland these were 'purpose targets', in the initial Sustainable Development Plans, in Wales there were headline indicators linked to the long-term targets. In both cases, this layering caused confusion and sent mixed messages: all indicators are equal but some are more equal than others. And in both cases, the renewal of the frameworks required by legislation in 2015 (the Well-being of Future Generations Act 2015 and the Community Empowerment (Scotland) Act 2015) provided an opportunity to refresh and remove the tiered approach.

There are also similarities in the characteristics of the wellbeing approach to governance, though these are less pronounced. Scotland and Wales have legislated for their frameworks, securing them past the next election. Northern Ireland has not done so due to the complexities of the Good Friday Agreement, there was no appetite at that point (preBrexit) to unpick the legislative framework for devolution. Northern Ireland also stands apart as the jurisdiction that has not sought to align the framework with the Sustainable Development Goals.

\section{Understanding the Impact of Wellbeing Frameworks on Approaches to Governance}

The introductory chapter set out the hypothesis that wellbeing frameworks are both a cause and a consequence of a new way of thinking about the role of governments. A move that continues the shift away from the top-down, one-size-fits-all approaches that characterised much of the welfare state across the UK in the 20th century. This chapter explores the extent to which we have evidence that the shift has moved beyond rhetoric to policy and social change.

In researching this book, my aim has been to tell a story of the development and implementation of wellbeing frameworks in such a way as to 
draw tentative but credible conclusions about the contribution made to advocacy, policy and social change in the three jurisdictions.

At the outset of this analysis, it is important to stress that Northern Ireland has had limited time to impact on social outcomes (though the local government duties came into effect in 2015). Abercrombie et al. identify that it takes seven to 10 years for successful changes to be implemented (2015). Scotland and Wales fit comfortably within this timescale but in both the cases, the legislative underpinning is relatively newboth passed legislation to secure the approach in 2015 and so impact from this legislation is just beginning to emerge.

\section{Wellbeing as a Goal}

Each framework has wellbeing clearly identified as a goal. Scotland's purpose statement is to 'focus on creating a more successful country, with opportunities for all of Scotland to flourish through increased wellbeing, and sustainable and inclusive economic growth.' Wales has opted for a legal definition which requires all public bodies to 'carry out sustainable development and improve and achieve economic, social, environmental and cultural well-being.' Northern Ireland sets the purpose of government as 'improving wellbeing for all - by tackling disadvantage and driving economic growth'. There are similarities of language here, but clear differences in the balance between economic, social and environmental wellbeing.

The wellbeing approaches that gave rise to these statements of goal or purpose were developed to solve different problems in each jurisdiction: problems of public services, problems of sustainable development and problems of political visioning. These are not mutually exclusive categories. In Scotland and Northern Ireland, there was a strand of 'beyond GDP' particularly from the non-governmental stakeholders. In Wales, legislation on sustainable development provided an opportunity to include a set of powers and duties relating to the culture of public services.

Over time, the narratives around the wellbeing frameworks have coalesced. Wales has moved into the space of public sector reform, while Scotland has aligned to the Sustainable Development Goals. Northern Ireland mixes public sector reform aims at the devolved level with sustainable development aims at the local level. 
The wellbeing frameworks in Wales and Scotland are therefore an articulation of the need to rebalance decision-making, reducing the primacy given to economic decisions and placing more emphasis on the social and environmental outcomes and on equality more broadly. Despite these intentions, the dominance of economic thinking can be seen in the political narratives of each jurisdiction.

Our society is crying out for a more ethical approach to finance, but we still return to the very criteria that got us into trouble in the first place. We promote the chase for AAA credit ratings, wealth generation becomes an end in itself rather than a means to an end and we end up promoting the values of greed and selfishness. (Kenneth Mackintosh, MSP speaking in the Scottish Parliament) (Mackintosh 2012, online)

Overall, there was therefore a strong sense that economic growth was the ultimate aim of the Welsh Government. (Michaelson 2013, p. 114)

While there is evidence of new narratives on balancing the domains of wellbeing, there is also evidence of the primacy given to economic outcomes in policy decisions. The debate in Scotland is often focused on the Purpose Statement and the weight it gives to economic outcomes (though a lot hinges on how you interpret 'sustainable economic growth'). Analysis of policy and legislation by Andrea Ross, Professor of Environmental Law at the University of Dundee, shows that the Scottish Government itself has not been consistent in how it defines sustainable economic growth (Ross 2015). For example, is it about balancing economic, social and environmental outcomes now or does it also have a reference to the future? The new National Performance Framework (NPF) goes someway to rectifying this by the use of the word 'wellbeing' but detractors continue to be concerned that the model does not challenge the dominance of economic thinking. This is a delicate balancing act for the SNP Government whose principal aim remains to secure Scottish independence from the UK. Experience from the 2014 referendum shows that economic arguments were decisive in the 'no' vote. Since that time, the Scottish Government has given considerable weight to the messages that it is a competent manager of the economy, most recently in a detailed analysis of the economic case for independence (Sustainable Growth Commission 2018). 
In Wales, Lang and Marsden (2017) chart the development of the Cardiff Capital Region City Deal and its focus on growth and investment potential. As the authors note, despite the legislative requirements of the Well-being of Future Generations Act 2015, 'economic growth is the primary metric against which the impact of the City Deal will be assessed by the UK Government' $(2017$, p. 10). This raises questions about the extent to which it is the political narrative within Wales which prioritises the economy, or whether it is subject to the UK government's approach to controlling the terms of the City Deals in devolved jurisdictions.

The experience in Wales provides useful insight into the use of sustainable development as a unifying narrative. They retain the strongest narrative connection to sustainable development with the focus on future generations. But their experience was that as a term, sustainable development was not able to mobilise and motivate across the public sector. The review of the first wellbeing assessments made by Public Services Boards found that in general, there was a lack of acknowledgement or evidence that specific issues, such as poverty, impact on many of the seven national wellbeing goals. There was a tendency to link poverty to the prosperous goal or equal goal, rather than integrating issues and seeking a holistic view of the local area (Future Generations Commissioner for Wales 2017). Interviewees reported that there were still instances where the wellbeing of future generations was seen as in tension with economic outcomes.

That wellbeing frameworks are not a substitute for political decision-making may seem obvious but goes to the heart of the limits of the evidence-informed policy. The OECD, in their submission to the Carnegie Roundtable on Measuring Wellbeing in Northern Ireland, offered words of caution about the limits of a wellbeing approach to policy: '[wellbeing] should not be understood as providing a technocratic solution to solve the prioritisation dilemmas that are at the heart of government - which concern values as much as numbers' (Doran et al. 2015, p. 17). The wellbeing frameworks is only one source of evidence in policy-making, and while it is one that has a role and weight attached to it, the real world of politics means that attention continues to be paid to inputs (the numbers of police on the street, class sizes, location of hospitals) and targets (waiting times for treatments, exam results being above the year before). There is a significant challenge here to raise media awareness of other measures and their benefits. To date, this is not a challenge that the devolved governments have embarked upon. 


\section{Wellbeing as a Conversation}

A common critique of the wellbeing frameworks is that the indicator sets do not seem to grab the public's, or perhaps more accurately the media's, attention the way that GDP does. There have been calls in Scotland for an official index of wellbeing, inspired by the Oxfam Humankind Index. This, it is argued, would provide a figure that works as a 'hook' to counter the effect of GDP. This is similar to the arguments used to support the use of headline subjective wellbeing indicators. However, as we have seen, this is not the approach taken by any of the three devolved governments. Professor Stiglitz offers this insight in his advice to the Scottish Parliament:

Let us not try to get everything into one number. Let us consider various dimensions and then discuss things. Are we not emphasising the environment enough? Are we not emphasising inequality enough? Are we not emphasising employment? Let us have a dialogue about that. (Scottish Parliament 2013, online)

Interviewees in Wales and Northern Ireland noted the tendency among the civil service to turn any number presented back into a target to be met. As one civil servant noted: 'indicators are just there to give you an indication of whether things are going well not a slavish set of targets'. But as Sophie Howe (Commissioner for Future Generations) reflected to me during her interview that it can be hard to present measurements in a way that supports a wellbeing approach: 'The biggest challenge to work through is the need to monitor and track the progress that's being made without driving the wrong sort of behaviours, where people chase the number as a target and create perverse consequences.'

Partial blame is attributed by interviewees to the powerful professional interest groups in favour of the status quo. While this is undoubtedly true, there is a more complex public narrative to consider, the role of the media in supporting the wellbeing approach was not proactively raised in any of the interviews for this book, nor did it appear in the desk-based analysis. But the media's obsession with inputs is as much an issue for public policy as its obsession with GDP. While of course there is an issue of leadership, it is understandable that no politician wishes to be the one pilloried in the press for slashing NHS budgets. 
There are practical as well as political reasons for the continued dominance of these targets, and indeed of GDP itself. Many of the indicators used in the wellbeing frameworks are reported annually, not weekly, monthly or quarterly; they are therefore both less immediate reflections on public services and less familiar to the media. They are issued when they become available and as such it is difficult to tell a coherent story. There is an assumption in much discussion on evidence into policy and practice that decisions will wait until there is sufficient evidence. The real politik does not support this ideal state with decisions made sometimes very quickly in response to a specific set of circumstances. That politicians attach significance to the timeliest data, even if it is not the most comprehensive or robust, is not surprising. Over time, the digital transformation and automation means that it is likely that national statistics will be replaced by administrative and personal data-Experian already knows more about the financial health of the UK than the Office of National Statistics. There are challenges here in relation to the balance between privacy, personalisation and public service improvement, but the direction of travel is clear (Scott 2018).

The move to using indicators as a conversation about social progress, what is working and what is working less well (or not at all) is slow to materialise. But the difficulty here is providing a clear story of the direction of travel for social progress. The wellbeing frameworks in Scotland, Wales and Northern Ireland provide robust information on which to monitor and evaluate the impact of government interventions. But they go further than merely reporting on statistical trends, they seek to analyse these trends within their specific policy context. In this way, the process can be seen as 'social reporting', described as information on social structures and processes, and on preconditions and consequences of social policy, regularly, in time, systematically and autonomously (National Economic and Social Council (Ireland) 2009, p. 49). We have seen in the preceding chapters that Wales was the most open and inclusive jurisdiction in the development of its wellbeing framework, with Scotland making recent improvements here. The engagement in Northern Ireland succeeded in terms of the governments' own expectations of the level of public participation, but this is less than that expected in the other jurisdictions.

The examples to date provide analysis of individual indicators and their contribution to National Outcomes in Wales and Scotland. But they stop short of providing an overall analysis of the direction of travel, 
or discussion of the interrelationships between different indicators and outcomes. There is still a sense of compartmentalisation within the reporting, clustering around traditional professions or old departmental groupings.

The new Scottish Government national performance website (in beta testing) is an attempt to break away from this by providing an interactive data tool which allows individual indicators to be examined by sub-group and 'pooled' for outcomes. Further, government analysts are cautious about ascribing causation to changes, which limits the ability of external stakeholders and the public to make use of the data to hold the government to account.

Governments as a whole appear cautious about overstating the importance of the indicators, perhaps aware that they are not always in control of the drivers of negative changes. But greater emphasis needs to be placed on telling this story. In their comments on the Scottish Government Consolidated Accounts, Audit Scotland (not known for throwing caution to the wind) reported that 'they [the Scottish Government] do not report on the performance of individual portfolios or the Scottish Government as a whole, limiting the reader's ability to see the Government's own contribution to national outcomes' (Auditor General for Scotland 2017, p. 18).

\section{Wellbeing as a Framework}

Each of the devolved governments has specifically set out to see public services, or the business of government, as a single system, and used the wellbeing framework to articulate these common goals. A wellbeing framework is therefore, potentially, a very powerful tool allowing the centre of government.

The framework in this sense is less of a set of supporting structures and more of a rhetorical device to emphasise the role and values of government, and in particular to signal a move to a different way of working.

Within the devolved governments, there were different approaches to the location of this responsibility for the framework. Northern Ireland developed its Centre of Government following the OECD review (OECD 2016), placing more emphasis on the newly restructured Executive Office (formerly the Office of the First Minister and Deputy 
First Minister). It is the Executive Office which oversees the draft Programme for Government, and hence the wellbeing framework.

In Wales, statutory powers on wellbeing are split between powers and duties to implement the Act (placed on Welsh Ministers, in particular, the Cabinet Secretary for Finance) and scrutiny powers located in both the Welsh Audit Office and the office of the Commissioner. The Commissioner for Future Generations in Wales has not as yet used her powers of review but in a memorandum of agreement with Welsh Audit Office, the two bodies have agreed to share information. This dual approach is seen by interviewees as particularly helpful for parts of the system that do not respond directly to the narratives on culture change, but who are influenced by budgets.

In Scotland, responsibility for the NPF sat for a number of years with the Deputy First Minister and Cabinet Secretary for Finance, the Constitution and the Economy, John Swinney MSP. While he retained the Deputy First Minister role in a 2017 reshuffle, he did not take the NPF with him; instead, it stayed with the Cabinet Secretary for Finance. Underneath the Ministerial remit, it has moved in 2018 to a clear ownership with the Director-General Scottish Exchequer who is responsible for the overall Scottish Budget including tax, spending and measuring performance, and for advice, support and systems on finance and procurement. Reflecting on the role of the Finance Ministry in Scotland, Sir John Elvidge told me that while its role is 'as a service function to the collective, it was conceived of as a team of people whose job it was to meet the objectives of the government, it is not the kind of dominant force that it is in most government structures'.

It is not yet clear whether the location of control of the wellbeing framework has any effect on the overall impact. There are advocacy advantages to the Commissioner in Wales being independent, being able to speak outside the system, as she has been doing on the M4 relief road inquiry. On the other hand, there may be policy advantages to being located close to central government decision-making, particularly related to prioritisation and budget setting. Being located within a central unit and connected to the Finance departments should have led to greater implementation of wellbeing as a whole-of-government approach.

Ideally, there should be a sense of cascading frameworks, with each level connected to the vision statement and outcomes set by the government. It is not at all clear that this is what has happened in any of the jurisdictions under study. The key document in the devolved 
governments is the Programme for Government which sets priorities for action. The Scottish Programme for Government makes little reference to the NPF. Wales retained the Programme for Government but link it clearly to the wellbeing goals through a wellbeing strategy. Northern Ireland reworked the approach to the Programme for Government completely transforming it into a wellbeing framework.

At the local level, the picture is similarly mixed. The legislative requirements in Wales have meant that public bodies have to move quickly to reflect the well-being goals into their own planning procedures. In Northern Ireland, local government requirements to plan for economic, social and environmental wellbeing pre-dated the draft framework but in practice, all local authorities have aligned to the draft Programme for Government outcomes. Scotland, despite the longest history, has the weakest connection between the former Single Outcome Agreements and the NPF. In all three cases, there is now a compulsion on local government to at least take account of societal wellbeing in the planning of its own work.

Even where the strategic links are clear, there is evidence of a lack of coherence. In conversations in all three jurisdictions, the health sector is singled out as a sector that has a weak alignment to the wellbeing frameworks. The health profession sees the ultimate goal to be improved health for all, rather than seeing health as one domain of wellbeing. Similar arguments on supremacy can be found elsewhere, for example in the environment, but these are not matched by the power held by the medical profession. One of the difficulties here is that there is no hierarchy of legislation in the legal systems of the devolved administrations, each Act (even when it duplicates or uses different definitions) has equal status. A wellbeing framework may have legislative weight, but it does not have any more weight than any other legislation. In the absence of clear connections to funding decisions, its power is muted.

One of the consistent barriers to impact from a wellbeing approach is the retention of traditional approaches to budgeting. The ambition of the wellbeing framework has not been met by changes in the budgeting process within governments. Shared responsibility for the outcome is not matched by shared budgets. In Northern Ireland, this is complicated by the strict rules on departmental authority created by the power-sharing agreement. More broadly, there is no consensus on how to budget for wellbeing approaches such as prevention. The approach taken in each jurisdiction has been to provide dedicated funding for intersectoral 
projects; these specific funds are by their nature relatively small in comparison to the budgets as a whole and can be vulnerable to cutbacks when funding is tight (Colgan et al. 2014).

In each case, the link between resources allocated and outcomes achieved is opaque, even where information is presented as part of the budgetary process. If wellbeing outcomes that cut across departmental boundaries are to become the primary focus of public policy, they need to be supported by appropriate budgetary processes. It is easy to see how a policy or programme that depends on resource inputs from a number of different departments may struggle without a clear process for allocation of funds. The kind of budgeting for outcomes envisaged would clearly be different in terms of both scale and approach.

\section{Wellbeing as an Approach}

There is broad recognition in political statements, policy documents and through the interviews carried out for this analysis, that a wellbeing approach is a significant culture change for the public sector. As former Finance and Personnel Minister, Simon Hamilton, and the former Chair of the Finance and Personnel Committee, Daithí McKay, noted in their joint statement on wellbeing in Northern Ireland, the global conversation about wellbeing is about much more than measurement. It is also about 'doing things differently'. Many of the conversations and interviews I had focused on wellbeing not as a framework of measurement but as a catalyst for change. For example, one civil servant I spoke to stated that their biggest surprise in working on the framework was that 'first and foremost this is a hearts and minds issue, it's a conversation with colleagues, it's a change process... it's not about writing clever policies, it's about delivering them and recognising that do to that we have to behave differently'.

To date, the culture change is most clearly evidenced at senior levels. Within the civil service, there is a point at which the agenda and policy formulation is decoupled from implementation. Aideen McGinley reflects on this in her interview with me: 'there's a layer in the middle of the civil service that is the hardest to convince - I call it the treacle layer'. From her perspective, this relates largely to an over-reliance on habits, or social norms (the sense of 'this is how we do it here'). Taking a behavioural science perspective, we can see that the various parts of the 'system' are not necessarily pushing in the same direction and that there are 
other levers that can be pulled to encourage culture change. For example, culture change can be reinforced through extrinsic motivation where it is built into performance management and reward systems, or intrinsic motivation by reinforcing the values of public service (see for example Northern Ireland Audit Office 2018).

Supporting culture shifts in the delivery of public services requires investment in capacity building programmes: 'If there is no change in system capacity, there will be no change. Managing complexity is one of the core capacities' (Colgan et al. 2016, p. 69). There were discussions, and references in policy documents to the role of a new type of civil servant, a boundary spanner whose job it is to help manage this complexity, with a range of transferable skills rather than expert knowledge in a defined policy area.

Moving to horizontal integration within government requires a different approach to performance management. Traditionally progression was secured through technical expertise rather than the skills required to work across departments and with different layers of government and external stakeholders. These skills include intellectual analysis, networking skills and systems thinking. Scotland is the only jurisdiction that tackled this issue head-on, constructing a new model of performance management that sees staff graduating to a greater focus on horizontal skills as they progress in the organisation. As Sir John Elvidge told me during his interview: 'The transition around what we will value and what we will reward was at the heart of the cultural change.' There is no clear evidence of the impact of this change yet though some cross-cutting groups have been set up to consider outcomes within the Scottish Government and including non-civil servant members.

Yet a notable gap in the interviews and analysis for this book is the extent to which wellbeing frameworks encourage those working in public services to behave differently, so that their activities are intrinsically beneficial to wellbeing rather than serving as a means to an end (Centre for Bhutan Studies and GNH 2017). There are far more examples of changing the structures and planning systems for public services (what public services are delivered, and by whom) than there are of changing behaviours in services (how public services are delivered).

In their review of policy recommendations on sustainable happiness (defined broadly not just subjectively), the Centre for Bhutan Studies and Gross National Happiness identified four themes that should be taken into account in making the analysis: 
- Supporting autonomy. Respecting the capacity of people to make decisions about their own lives.

- Supporting relationships. Recognising that people are social beings, operating within a set of family and community relationships.

- Supporting competence. Focussing on what an individual can do with a view to developing their ability to improve their own wellbeing.

- Supporting engagement. Recognising the importance of having a sense of purpose and encouraging and supporting people to engage in meaningful activity.

In their work on Beyond GDP, Social Justice Ireland developed a similar set of wellbeing tests that should be applied to programmes (Reynolds and Healy 2009). Here the goal of wellbeing in policy implementation is not to reform public services or restructure them, but rather to deliver services in a way that maximises wellbeing.

What would such a wellbeing approach to governance look like in practice?

It would almost certainly involve a decisive shift towards prevention. For much of the post-war period, the dominant focus of intensive social policy interventions was on those identified as 'in need', classified as such through legislation. This approach required individuals and families to evidence problems (or for professionals to identify them as such) before being able to access support. Muir describes the current model as follows:

If one looks across the majority of mainstream services, they are generally of this reactive kind: the police service is mainly focused on solving crimes and catching criminals, hospitals are about treating and caring for people once they have become sick and prisons effectively warehouse offenders, successfully rehabilitating only a minority. (Muir 2012, p. 10)

Moving from crisis intervention to prevention has been a key discussion in public policy, and one that each of the three jurisdictions have embraced. But impact is clearly hampered by a lack of shared definition within and between jurisdictions, something also noted as problematic by the National Audit Office (2013). From the work that has taken place in the three jurisdictions, we can see a number of programmes that are delivering upstream preventative public services. These can help us map out what prevention in action looks like: 
- From institutions to community-based interventions (health and justice).

- From prescribing antidepressants to social prescribing.

- From antisocial behaviour interventions to whole-family support programmes.

The language of wellbeing certainly supports a shift to prevention but the impact to date is not overwhelming. Wales does identify prevention as one of the five ways of working for wellbeing, in Scotland and Northern Ireland, the narrative is more focused on the impact of austerity on public sector budgets and the need to drive efficiencies. As noted above, while there has been a shift in the narrative on the importance of prevention, particularly for children and young people, there has not been a corresponding shift in budgets to support it.

The second clear area of policy change that a wellbeing approach would require is co-production, going further than consultation and engagement by recognising the intrinsic power within citizens to act to improve their own wellbeing. There are two levels of co-production: co-design of services and co-delivery of outcomes.

Within the co-design of services, people are acting as citizens, engaging locally or at devolved level to influence the design of public services. At a devolved level, none of the jurisdictions measure voting as an indicator of wellbeing, though it is a standard indicator in international indexes. There is a preference for measuring 'influence over local decisions', though of course this is not a measure of the success of the devolved governments at engaging with their citizens, but rather of local government. At a community level, each jurisdiction struggles with articulating the difference between volunteering and supporting strong community relationships. The frameworks and documents overemphasise the role of organised activities and organisations and underestimate the importance of places and spaces for people to interact without a public-sector agenda (Ferguson 2017).

The evidence for a shift towards co-production is stronger at an individual level, there is more emphasis on the active engagement in service delivery for outcomes, particularly in health and social care. The frameworks do make some reference to these issues, Scotland for example has recently introduced indicators that will measure the extent to which young people feel their views are listened to and respected. 
While there is evidence of a shift towards a wellbeing approach, it is not overwhelming. The activities appear to remain on the margins of public services rather than being a 'golden thread'. The traditional view of public services as being done to someone in need still dominates.

In the introduction, I quoted McGregor and Pouw in their identification of the three allocative mechanisms for moving resources around society:

1. Individuals, households and communities. Based on reciprocity and mutual support.

2. Private sector. Based on market exchange.

3. Public sector. Based on redistribution and regulation (2017).

The traditional economist view clearly overstates the role of the private sector. The traditional welfare state overstates the role of the public sector. The wellbeing approach calls on both to be rebalanced by recognising the role that individual, households and communities play in improving their own wellbeing.

\section{The Challenges Ahead for Wellbeing Approaches}

Reflecting on the wellbeing frameworks and approaches it is easy to conclude that they are stable parts of the machinery of policy-making and governance in each of the jurisdictions. Their legislative basis, the support from within the system and from across political parties makes them relatively secure. Their impact however is not guaranteed. There are three key challenges that each government ought to address.

The first challenge is to understand the key role of the wellbeing framework as a communications tool to frame the work of the governments. They tell us something about who we are as a society and where we are going. The communication is both internal to public services and external to citizens. Within public services, many will need convincing of the effectiveness of the approach and yet scant attention is paid to providing those within the system with clear stories of impact that they can understand and articulate to others. Similarly, far more attention needs to be paid to communicating the content of the frameworks to the public and sparking a conversation about social progress.

The second challenge is to allow the frameworks to breathe and evolve in different parts of the system. Within public services, the 
language used to assess impact by those in senior positions is that they are seeking alignment, a golden thread between different parts of the system. What they are not seeking is mindless duplication or cut-and-paste policy-making. There is a risk that in seeking clear impact, conformity on outcomes and indicators is what is measured and expected, rather than conformity around the spirit of the approach. In the relationship between public services and citizens and communities a similar 'letting go' is required. The framework document may belong to the government, but societal wellbeing belongs to all citizens. There is a risk that by taking responsibility for all aspects of wellbeing other activities are crowded out or displaced. More attention needs to be paid to the contribution of people to our own individual and collective wellbeing with government playing a supporting and enabling role rather than a provider role.

The final challenge is to support leadership for culture change from diffuse places and people. The development of wellbeing frameworks owes much to a small number of people who took a risk and wanted to try something different. But their success in implementation has many leaders, from different sectors and professions. Public services are good at supporting leadership at the centre, for wellbeing approaches to be successful there will have to be ways of supporting leaders wherever they emerge.

\section{REFERENCES}

Abercrombie, R., Harries, E., \& Wharton, R. (2015). Systems Change: A Guide on What It Is and How to Do It. London: New Philanthropy Capital.

Auditor General for Scotland. (2017). The 2016/17 Audit of the Scottish Government Consolidated Accounts. Edinburgh: Audit Scotland.

Centre for Bhutan Studies and GNH. (2017). Happiness: Transforming the Development Landscape. Thimphu, Bhutan: Centre for Bhutan Studies and GNH.

Colgan, A., Kennedy, L. A., \& Doherty, N. (2014). A Primer on Implemenfing Whole of Government Approaches. Dublin: Centre for Effective Services.

Colgan, A., Rochford, S., \& Burke, K. (2016). Implementing Public Service Reform-Messages from the Literature. Dublin: Centre for Effective Services.

Doran, P., Wallace, J., \& Woods, J. (2015). Towards a Wellbeing Framework: Background Report Prepared for the Roundtable on Measuring Wellbeing in Northern Ireland. Dunfermline: Carnegie UK Trust.

Ferguson, Z. (2017). The Place of Kindness. Dunfermline: Carnegie UK Trust. 
Future Generations Commissioner for Wales. (2017). Well-Being in Wales: Planning Today for a Better Tomorrow. Cardiff: Future Generations Commissioner for Wales.

Lang, M., \& Marsden, T. (2017). Rethinking Growth: Towards the Well-Being Economy. Cardiff: Sustainable Places Research Institute.

Mackintosh, K. (2012). Scottish Parliament Debate on the Humankind Index [Online]. Available at: www.parliament.scot. Accessed June 2018.

McGregor, J. A., \& Pouw, N. (2017). Towards an Economics of Well-Being. Cambridge Journal of Economics, 41(4), 1123-1142.

Michaelson, J. (2013). The Use of Sustainability Indicators in the Welsh Government. London: New Economics Foundation.

Muir, R. (2012). The Long View: Public Services and Public Spending in 2030. London: IPPR.

National Audit Office. (2013). Early Action: Landscape Review. London: National Audit Office.

National Economic and Social Council (Ireland). (2009). Well-Being Matters: A Social Report for Ireland. Dublin: National Economic and Social Development Office (Ireland).

Northern Ireland Audit Office. (2018). Performance Management for Outcomes. Belfast: Northern Ireland Audit Office.

Nussbaum, M. (2006). Frontiers of Justice: Disability, Nationality, Species Membership. Cambridge: Harvard University Press.

OECD. (2016). Public Governance Review of Northern Ireland. Paris: OECD.

Reynolds, B., \& Healy, S. (2009). Beyond GDP: What Is Prosperity and How Should It Be Measured? Dublin: Social Justice Ireland.

Ross, A. (2015). The Future Scotland Wants-Is It Really All About Sustainable Economic Growth? Edinburgh Law Review, 19(1), 66-100.

Scott, K. (2018). Data for Public Benefit. Dunfermline: Carnegie UK Trust.

Scottish Parliament. (2013, February 27). Economy, Energy and Tourism Committee [Online]. Available at: http://www.parliament.scot/parliamentarybusiness $/$ report aspx $? \mathrm{r}=8026 \& \mathrm{i}=73026 \& \mathrm{c}=1464690 \& \mathrm{~s}=$ humankind. Accessed 2018.

Sustainable Growth Commission. (2018). Scotland-The Case for New Optimism: A Strategy for Inter-generational Economic Renaissance. Edinburgh: Scottish Government.

White, D. (2018). Can We Measure Up to 'Good Work for All' Ambitions? [Online]. Available at: https://www.carnegieuktrust.org.uk/blog/can-measure-good-work-ambitions/. Accessed June 2018. 
Open Access This chapter is licensed under the terms of the Creative Commons Attribution 4.0 International License (http://creativecommons.org/licenses/ by $/ 4.0 /)$, which permits use, sharing, adaptation, distribution and reproduction in any medium or format, as long as you give appropriate credit to the original author(s) and the source, provide a link to the Creative Commons license and indicate if changes were made.

The images or other third party material in this chapter are included in the chapter's Creative Commons license, unless indicated otherwise in a credit line to the material. If material is not included in the chapter's Creative Commons license and your intended use is not permitted by statutory regulation or exceeds the permitted use, you will need to obtain permission directly from the copyright holder.

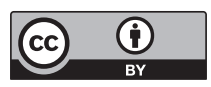

